\title{
Estudo de caso sobre as dificuldades de aprendizagem de alunos surdos na disciplina de Química
}

Cláudia Celeste Schuindt claudiaschuindt.cs@gmail.com cid.org/0000-0001-5112-2129 Universidade Federal do Paraná (UFPR), Curitiba, Paraná, Brasi

Clarianna Ferreira de Matos clarianna@ufpr.br

orcid.org/0000-0002-8848-7495 Universidade Federal do Paraná (UFPR), Curitiba, Paraná, Brasil

Camila Silveira da Silva camila@quimica.ufpr.br Universidade Federal do Paraná (UFPR), Curitiba, Paraná, Brasil

\section{RESUMO}

O presente trabalho analisa as dificuldades de aprendizagem na disciplina de Química, na perspectiva de alunos surdos inseridos em uma escola regular na rede estadual de ensino, constituindo uma pesquisa de cunho qualitativo do tipo Estudo de Caso. Com o aporte bibliográfico que fundamenta a Educação Inclusiva e tendo a observação como um instrumento fundamental para a constituição de dados foram acompanhadas 20 aulas de Química, ao longo de 12 semanas. Um questionário foi aplicado junto aos oito estudantes surdos de uma turma, para diagnóstico de perfil dos sujeitos de pesquisa e seleção dos educandos que participariam da etapa posterior, contemplando uma entrevista. Assim, três alunos - que atendiam aos critérios estabelecidos: possuir surdez total, não utilizar aparelho auditivo, compreender ao menos parcialmente a Língua Portuguesa - participaram da entrevista estruturada com o intuito de identificar quais eram as suas percepções e dificuldades na disciplina escolar em questão. Os resultados revelaram que o maior obstáculo de aprendizagem em Química é a diferença linguística, seguida da falta de conhecimento de LIBRAS pelo professor, da dificuldade na compreensão de sinais de terminologias químicas já existentes ou na criação de novos sinais, a não formação acadêmica específica dos intérpretes e a ausência de materiais didáticos em LIBRAS e de metodologias que façam uso de imagens como recursos didáticos. Assim, sinalizamos a importância de aprimorar os materiais e metodologias de ensino que atendam as particularidades de uma classe de inclusão, conhecendo as necessidades apontadas pelos próprios educandos surdos.

PALAVRAS-CHAVE: Dificuldades de aprendizagem. Química. Alunos surdos. Ensino de Química. 


\section{A EDUCAÇÃO INCLUSIVA E A DIFICULDADE DE APRENDIZAGEM NO ENSINO DE CIÊNCIAS/QUÍMICA}

A Educação Inclusiva no Ensino de Ciências/Química é um campo de pesquisa em expansão, tendo suas discussões ampliadas a partir da promulgação da Lei da Inclusão - Lei 10.436, 24 de abril de 2002 (BRASIL, 2002), que dispõe sobre a Língua Brasileira de Sinais - LIBRAS. Mais recentemente, o Decreto 5626/05 (BRASIL, 2005), que regulamenta as Leis 10.098/94 (BRASIL 1996) e 10.436/02 (BRASIL, 2002) e orienta ações para o atendimento à pessoa surda, inclui a LIBRAS nos currículos de magistério e cursos de licenciatura, e a inserção de alunos surdos em escolas de ensino regular. Mas, ainda temos muito a investigar sobre esse cenário e as particularidades das situações educativas que envolvem o processo de ensino e aprendizagem de Ciências, bem como a formação docente para a inclusão (LIPPE; CAMARGO, 2009).

O reconhecimento da LIBRAS como meio de comunicação das pessoas surdas, por meio da Lei no 10.436/2002 tornou obrigatório o ensino dessa Língua nos cursos de Licenciatura. A proposta - que integra os pressupostos básicos da referida legislação - foi regulamentada pelo Decreto Federal número 5.626, de 22 de dezembro de 2005, e em seu artigo 3으, especifica a inclusão da LIBRAS como disciplina curricular obrigatória também nos cursos de formação de professores, em níveis médio e superior e como disciplina curricular optativa nos demais cursos de Educação Superior e na Educação Profissional.

Segundo Spenassato e Giareta (2009) a inclusão da disciplina de LIBRAS nas matrizes curriculares dos cursos de Licenciatura em Biologia foi de extrema importância, pois despertou a atenção dos pesquisadores da área para o tema, assim como a maneira como os alunos surdos são inseridos no sistema de ensino. Destacamos que o nosso interesse pela cultura surda e como ocorre o processo de ensino e aprendizagem dos alunos matriculados na Educação Básica regular pública, frente à disciplina de Química, também surgiu após cursar a disciplina de LIBRAS, no Curso de Licenciatura em Química.

Nessa perspectiva, a atenção para as questões da Educação Inclusiva no Ensino de Química passou a ganhar destaque por parte de pesquisadores, principalmente no tocante ao uso de novas metodologias e recursos didáticos que atendam às necessidades dos alunos surdos e ouvintes. A educação de surdos, que antes acontecia, geralmente, em escolas especiais, passou a se dar em escolas regulares e, essa mudança, trouxe à tona a preocupação de como esses alunos estão aprendendo, pois o conhecimento científico é de primordial importância para a formação dos indivíduos, já que os cidadãos necessitam, constantemente, tomar decisões que envolvam assuntos científicos (SANTOS; SCHNETZLER, 2003). A literatura especializada nos mostra que muito se pesquisa sobre os obstáculos de aprendizagem apresentados por alunos ouvintes na disciplina de Química e pouco por alunos surdos (ALMEIDA; TEIXEIRA, 2011). Em relação a esses últimos, as pesquisas que relatam especificamente os obstáculos de aprendizagem inerentes à disciplina de Química ainda são escassas.

Das investigações desenvolvidas e que tomamos contato, essas revelam que a importância de diagnosticar as dificuldades que os alunos surdos enfrentam em sala de aula ultrapassa a divisão disciplinar estabelecida pelo sistema educacional (MONTEIRO, 2011). Assim, é urgente e necessária a propagação de metodologias 
e recursos auxiliares na educação dos surdos que sejam desenvolvidas a partir das necessidades específicas desse grupo (MORAES et al., 2004). As diversas subáreas das Ciências da Natureza têm voltado sua atenção ao ensino inclusivo, seus fundamentos e as metodologias utilizadas. Como exemplos, temos estudos com foco na mediação entre intérprete-professor (AROLDO JUNIOR; RAMOS, 2008); nas concepções dos alunos a respeito dos materiais didáticos e qual a aplicabilidade deles (ROCHA et al., 2015); em metodologias alternativas, na estrutura escolar, e no relacionamento entre professor-aluno, aluno-intérprete e professor-intérprete (RAMOS, 2011) e; na relação do professor da disciplina com o professor intérprete no processo educativo (SPENASSATO; GIARETA, 2009).

Em pesquisa sobre as terminologias químicas em LIBRAS, Sousa e Silveira (2011), constituíram dados a partir de entrevistas feitas com professores e intérpretes focando na opinião destes sobre as dificuldades de ensinar Química para surdos. Em seu trabalho, a respeito de Química e Surdez, Vilela-Ribeiro e Benite (2010), aplicaram um questionário aos intérpretes e solicitaram auxílio deles para que uma entrevista semiestruturada fosse feita com os alunos, abordando a interação social entre eles, com os professores e a relação com a Química em geral.

Lorenzetti (2001) analisou a compreensão de seis professores a respeito da inclusão de alunos surdos em uma escola regular, sendo que alguns deles afirmaram que não há ganho algum aos educandos, pois os mesmos não têm condições físicas para acompanhar os demais estudantes. Contudo, o autor enfatiza que a escola deve adequar-se ao aluno e não o oposto, de modo que a singularidade do estudante seja respeitada. Caso semelhante é observado na entrevista feita por Schneider (2006), quando professores demonstraram interesse em realizar práticas educacionais inclusivas com os alunos surdos e não tiveram a formação necessária, sinalizando que a diferença entre as línguas se torna um fator primordial no processo de ensino-aprendizagem. Quanto à aprendizagem, alguns professores afirmaram que os alunos surdos estavam inseridos no contexto da normalidade, porém, outros comentaram que a aprendizagem era mais lenta. Essa concepção equivocada que o professor forma a respeito do aluno, influencia diretamente em suas atitudes e comportamento dentro da sala de aula. Ou seja, apesar do estudante surdo ser dotado de potencial para desenvolver todas as atividades da mesma forma que um aluno ouvinte, acaba sendo tratado como se tivesse uma dificuldade impossível de ser ultrapassada (SILVA; PEREIRA, 2003).

Para Guarinello et al. (2006), os professores não relacionam seus obstáculos para ensinar com as dificuldades de seus alunos para aprender, como se o desconhecimento dos docentes acerca da surdez, a complexidade da interação com o discente, o relacionamento e o conhecimento de LIBRAS, por exemplo, não tivessem implicações diretas e significativas na aprendizagem dos surdos. Em relação à presença do intérprete, Almeida e Teixeira (2011) apontam que há uma insatisfação atrelada à falta de formação necessária para suprir as dificuldades do aluno em cada disciplina. Por ser formado, majoritariamente, em Letras-LIBRAS, esse profissional não é plenamente capaz de sanar dúvidas relacionadas a conceitos científicos em sala de aula, uma vez que cabe a ele apenas o papel de intermediador na comunicação entre os sujeitos. Entretanto, muitas vezes, ele assume a função de explicar os conceitos e não só de realizar a interpretação/tradução, e essa prática normalmente ocorre pelo fato do 
estudante surdo conseguir se comunicar melhor com esse profissional do que com o professor.

Segundo Santiago (2014), a maior dificuldade em traduzir e interpretar os temas abordados em sala de aula está relacionada à variedade linguística apresentada pelos discentes. Esse obstáculo está vinculado ao pouco conhecimento dos sinais referentes aos conteúdos científicos, fato que tem prejudicado o estudante durante aulas como as de Química e provocando a desmotivação dos alunos. O trabalho desenvolvido por Barbosa e Pacheco (2014), sobre novas propostas para o ensino de Química inclusivo, apontaram como principais limitações de aprendizagem: a complexidade do conteúdo; as dificuldades de interação com os demais alunos durante as aulas; o fato de grande parte dos professores não serem proficientes na Língua Brasileira de Sinais LIBRAS; muitas terminologias químicas não possuírem sinal em LIBRAS e; principalmente, a ausência de recursos didáticos na língua mãe da comunidade surda. O despreparo por parte dos professores e intérpretes para o ensino e aprendizagem da Química para surdos pode acarretar no analfabetismo científico e tecnológico desses alunos, contribuindo para a exclusão deles, ampliando esse já dilatado índice.

De acordo com Vygotsky (1991), o homem é o produto de um conjunto de interações histórico-culturais, sendo que essas determinam o que e como o sujeito internalizará os conceitos. Em sua proposta, a questão central está em torno de como as condições sociais podem modelar a mente e construir o psiquismo, ou seja, em como as ferramentas culturais utilizadas, tais como a linguagem, têm a função de gerar e organizar os processos psicológicos, já que ela é entendida, nesta perspectiva, enquanto comunicação e, portanto, é anterior ao surgimento das palavras. Vygotsky vê a consciência como um engendramento social a partir do qual os homens exercem uma relação permeada de significados por mediação de signos. Assim, a linguagem passa a ser o instrumento que age internamente no indivíduo e causa transformação interna possibilitando a passagem do homem de ser biológico a ser sócio histórico, permitindo que este esteja inserido em seu meio social.

Na perspectiva do referido autor, considerando os processos educativos, o desempenho do aluno está intrinsicamente relacionado à Zona de Desenvolvimento Proximal - ZDP (VYGOTSKY, 2008), que pode ser observada quando sua capacidade em dominar novas habilidades ainda está em sua fase latente e será ampliada na medida em que haja interação com o ambiente, no caso, quando essa troca de experiências é favorecida dentro do espaço escolar. Para ele, é necessário reconsiderar não somente como as capacidades cognitivas são concebidas, mas também como estas são avaliadas, fugindo de um método de avaliação estático no qual a evolução da aprendizagem está focada nas respostas assertivas ou incorretas que servem como degraus para uma sequência gradual a fim de encaminhar a solução do problema.

Para Vygotsky (2008), é fundamental que haja interesse na capacidade do aluno, para que suas necessidades sirvam como base para avaliar a sua ZDP, uma vez que esta passa a ser um indicativo da extensão de quanto o discente pode evoluir além de quaisquer necessidades especiais físicas e motoras que possa haver.

De acordo com Neto et al. (2007, p. 8): 
Tem-se deixado de lado o desvendamento da questão na sua totalidade, associando-a a uma visão filo e ontogenética de desenvolvimento humano. [...] Ao invés disso, são reproduzidas no cotidiano de sala de aula estratégias consideradas eficazes no ensino de pessoas ouvintes ou mesmo práticas adaptadas aos surdos, mas sem uma base cognitiva que dê sentido a essas ações. Na maioria das vezes as questões relativas ao ensino sempre foram muito consideradas apenas a partir da ótica dos professores envolvidos no processo. [...] Ninguém mais adequado do que o próprio surdo para esclarecer suas necessidades mais vitais e assim orientar possiveis caminhos a serem trilhados pela escola.

A partir de tais observações, fica clara a necessidade de aprofundamento no entendimento do processo de ensino e aprendizagem, na perspectiva do aluno surdo. Assim, o presente trabalho pretende contribuir com a área, diagnosticando e analisando as dificuldades de alunos surdos, em escola regular, na disciplina de Química. Desse modo, delineou-se como norteadora desta pesquisa a seguinte questão: quais são as dificuldades de aprendizagem na disciplina de Química, relatadas por alunos surdos, inseridos em uma escola regular?

\section{OS CAMINHOS METODOLÓGICOS DA PESQUISA}

A presente pesquisa é de cunho qualitativo porque busca percepções e entendimentos sobre a natureza geral de uma questão, abrindo espaço para a interpretação (GERHARDT; SILVEIRA, 2009). Desenvolvemos um Estudo de Caso, retratado por Stake (1995) como sendo uma estratégia de pesquisa caracterizada pelo interesse em fatos e não exclusivamente em métodos de investigação, os quais podem ser tanto qualitativos como quantitativos. Algumas características podem estar dentro do sistema, nos limites do caso, e nem sempre é fácil para o pesquisador dizer onde termina o indivíduo e começa o contexto.

Considerando um grupo de alunos, numa determinada condição, a surdez, estes devem ser estudados de forma individualizada, embora a influência de diferentes aspectos que se ligam a esse sistema, como o contexto físico, sociocultural e histórico em que estão inseridos, não possam ser ignorados. De acordo com Yin (2001), o Estudo de Caso é a melhor estratégia quando se quer responder qual a dificuldade de determinado grupo e porque isso acontece, de modo a considerar uma unidade social como um todo.

Segundo Gil (2002) uma das características do Estudo de Caso é descrever o que é relevante em determinada população, para tal, é necessário o uso de técnicas que padronizem a constituição de dados a fim de sistematiza-la entre os indivíduos, para tal, foi feita uma triagem buscando estabelecer o perfil dos alunos surdos com o objetivo de averiguar questões como tipo de surdez, se total ou parcial, uso de aparelho auditivo, ente outras e selecionar quais sujeitos fariam parte da etapa subsequente da pesquisa.Ele deve reunir, tanto quanto possível, informações detalhadas para caracterizar a totalidade de uma situação. Segundo o autor, uma pesquisa assim categorizada, deve se concentrar em um assunto específico, nesse caso, a dificuldade de aprendizagem, na perspectiva de alunos surdos, na disciplina de Química, inseridos em uma escola regular na rede pública de Curitiba - PR.

A partir da definição de nosso objeto de estudo, foram feitos os levantamentos dos principais trabalhos científicos já realizados na área e da 
fundamentação legal da inclusão de alunos surdos na escola regular. Em seguida, a escolha do campo onde a pesquisa se desenvolveu se deu a partir da análise dos dados fornecidos pela Secretaria de Estado da Educação do Paraná, que traziam informações a respeito de quais escolas tinham turmas de inclusão e o número de alunos, assim, a investigação aconteceu no espaço escolar com o maior número de discentes surdos. A fim de caracterizar a escola, foram analisados o Projeto Político Pedagógico - PPP, o histórico da escola, sua estrutura física e funcionamento. Também foi avaliado o planejamento escolar e o que os documentos oficiais da escola traziam a respeito das aulas de Química e se esses estão de acordo com a Legislação que regulamenta o Ensino Inclusivo.

Num segundo momento de desenvolvimento da pesquisa, foi realizada uma observação de campo para a constituição de demais dados sobre os elementos da realidade escolar do aluno. A observação ajudou as pesquisadoras a "identificar e obter provas a respeito de objetivos sobre os quais os indivíduos não têm consciência, mas que orientam seu comportamento" (LAKATOS; MARCONI, 1996). Além disso, a pesquisa permitiu que tivéssemos contato direto com o caso a ser estudado, possibilitando uma investigação aprofundada a respeito do ambiente pesquisado.

De acordo com Ludke et al. (2013), para que a observação possa ser considerada confiável ela deve ser controlada e sistemática, o que requer um planejamento detalhado do trabalho e uma preparação minuciosa do observador, para que possa saber como deve se portar e se posicionar frente ao campo de pesquisa. As autoras classificam a observação como um dos principais instrumentos de constituição de dados em pesquisas qualitativas, pois promove o contato direto com o objeto de estudo e permite ao pesquisador a verificação de aspectos relevantes. Além disso, permite que o observador se aproxime da perspectiva dos sujeitos e se revela de extrema utilidade na descoberta de aspectos novos de um problema, o que justifica a sua utilização durante a execução desse projeto, já que sua finalidade era diagnosticar quais dificuldades os alunos surdos apresentam, e como citado anteriormente, esse campo ainda não apresenta dados substanciais. Por último, a observação permite a construção de dados em situações em que é inviável estabelecer outras formas de levantamento ou outras formas de comunicação sem que o meio seja influenciado pelo pesquisador.

Deste modo, no presente estudo, a observação foi realizada in loco, com o acompanhamento das aulas de Química de uma turma de segundo ano do Ensino Médio de um Colégio Estadual, localizado na região central de Curitiba/PR, que tem 16 alunos, dos quais, oito são surdos, todos devidamente matriculados no Ensino Médio regular em 2016. Esse colégio foi escolhido por vários motivos: localização, grande número de alunos de inclusão matriculados e inseridos em turmas mistas, ter de grande porte. A escola possui 17 turmas somente no Ensino Médio e destas, seis serem de inclusão, possuir boa infraestrutura e ser conhecido na cidade por acolher a comunidade surda. A observação foi realizada por 12 semanas, tendo 20 aulas observadas, com registros em diário de campo direcionados aos materiais e metodologias adotados; às aulas experimentais; à escala de trabalho sazonal dos intérpretes e a influência dessa prática; ao relacionamento entre professor, alunos e intérpretes; e à aplicação das provas trimestrais e o comportamento dos estudantes durante esse período. 
O instrumento utilizado nesse momento foi um questionário com questões fechadas (SILVA; MENEZES, 2005), onde se era possível responder Sim ou Não, em Língua Portuguesa, e com aplicação presencial. No Quadro 1 são elencadas as questões elaboradas e as suas justificativas.

Quadro 1 - Questões abordadas no questionário de triagem e seus objetivos

\begin{tabular}{|c|c|}
\hline Questão & Objetivos \\
\hline Você possui surdez total ou parcial? & $\begin{array}{l}\text { Identificar quais alunos possuem surdez } \\
\text { total ou parcial. }\end{array}$ \\
\hline Você usa aparelho auditivo? & $\begin{array}{l}\text { Identificar quais alunos utilizam aparelho } \\
\text { auditivo. }\end{array}$ \\
\hline Qual a primeira língua que você aprendeu? & $\begin{array}{l}\text { Verificar quais alunos tiveram contato com a } \\
\text { LIBRAS antes de ingressarem na escola } \\
\text { regular. }\end{array}$ \\
\hline Você sempre estudou em turmas mistas? & $\begin{array}{l}\text { Identificar quais alunos já tiveram a } \\
\text { experiência de estudar em turmas mistas. }\end{array}$ \\
\hline $\begin{array}{l}\text { Você entende frases inteiras escritas em } \\
\text { Língua Portuguesa? }\end{array}$ & $\begin{array}{l}\text { Verificar qual é o grau de compreensão } \\
\text { desses alunos frente à Língua Portuguesa } \\
\text { escrita. }\end{array}$ \\
\hline $\begin{array}{l}\text { Você entende frases inteiras escritas em } \\
\text { Inglês ou outro idioma estrangeiro? }\end{array}$ & $\begin{array}{l}\text { Verificar se esses alunos têm conhecimento } \\
\text { em outro idioma escrito. }\end{array}$ \\
\hline Você é fluente em LIBRAS? & $\begin{array}{l}\text { Identificar quais alunos declaram ter fluência } \\
\text { em LIBRAS. }\end{array}$ \\
\hline $\begin{array}{l}\text { Você é acompanhado por um intérprete } \\
\text { durante as aulas? }\end{array}$ & $\begin{array}{l}\text { Verificar se os alunos tinham o } \\
\text { acompanhamento do intérprete durante a } \\
\text { aula. }\end{array}$ \\
\hline $\begin{array}{l}\text { Você estudou no colégio desde o } 19 \text { ano do } \\
\text { Ensino Médio? }\end{array}$ & $\begin{array}{l}\text { Identificar quais alunos já tinham contato } \\
\text { com a metodologia da escola. }\end{array}$ \\
\hline Você já reprovou alguma série? Se sim, qual? & $\begin{array}{l}\text { Verificar se havia muitas reprovações e em } \\
\text { qual estágio da escolarização elas } \\
\text { costumaram acontecer. }\end{array}$ \\
\hline $\begin{array}{l}\text { Os seus colegas ouvintes tem bom } \\
\text { relacionamento com você? }\end{array}$ & $\begin{array}{l}\text { Verificar se os alunos tinham bom } \\
\text { relacionamento com os colegas ouvintes. }\end{array}$ \\
\hline $\begin{array}{l}\text { Você costuma estudar sozinho em casa pelos } \\
\text { livros ou utilizando a internet? }\end{array}$ & $\begin{array}{l}\text { Verificar se esses alunos costumavam } \\
\text { estudar sozinhos, fora da sala de aula. }\end{array}$ \\
\hline
\end{tabular}

Fonte: Autoria própria (2017).

Após traçar os perfis sociológicos e selecionar quais seriam os participantes da etapa seguinte da pesquisa, uma entrevista foi realizada com três educandos, com questões pré-estruturadas em Língua Portuguesa. Porém, como esta não é a língua mãe dos sujeitos, as perguntas foram traduzidas para LIBRAS por um profissional com atuação regulamentada pela Federação Nacional de Educação e Integração dos Surdos - Feneis/RS a fim de que a individualidade linguística dos alunos fosse respeitada e que os mesmos pudessem ter uma real compreensão dos questionamentos, com o intuito de assegurar a confiabilidade do método adotado para esta pesquisa. Para Gil (2002), a entrevista possibilita ao pesquisador um movimento em torno das questões permitindo que vários aspectos sejam tratados. Neste caso, o Roteiro de Entrevista contemplou questões abertas e discursivas que versavam sobre a disciplina de Química e seus aspectos didáticos. A entrevista teve seu Roteiro impresso e projetado em vídeo com a tradução em LIBRAS. 
Após a conclusão dessa etapa as respostas foram transcritas e analisadas segundo a metodologia de Análise de Conteúdo, na perspectiva de Bardin (1977), que propõe uma análise sistemática de materiais baseada na pré-análise, na inferência e na interpretação. Inicialmente as repostas foram lidas e transcritas para o meio digital, possibilitando a criação de um plano de análise. Após uma releitura cuidadosa, foi possível definir a unidade de significado a partir dos temas estabelecidos pelas autoras - afinidade com a disciplina; dificuldades de aprendizagem; relação com o professor e o intérprete; LIBRAS e a Química possibilitando o agrupamento do conjunto de dados em amostras menores. Uma vez reunidas, foi possível criar categorias analíticas pertinentes à interpretação dos dados (BARDIN, 1977).

\section{RESULTADOS E DISCUSSÕES}

Analisando o questionário, constatamos que de oito alunos, seis possuem surdez total. Quatro alunos têm LIBRAS como primeira Língua, e três sempre estudaram em turmas mistas, sete são acompanhados por intérpretes e seis são alunos desta escola há mais de um ano. Seis dos oito alunos surdos são repetentes, com pelo menos uma reprovação no histórico escolar. Sete responderam entender parcialmente frases escritas em Língua Portuguesa e um totalmente. Dos oito alunos, sete são fluentes em LIBRAS e apenas um, com surdez parcial, não se considera fluente na Língua Brasileira de Sinais. Quatro alunos utilizam aparelho auditivo e sete tem computador com acesso à internet. Seis deles estudam sozinhos, têm bom relacionamento com ouvintes e todos pretendem prestar vestibular. A partir desses resultados, foram selecionados os estudantes para participarem da próxima etapa da pesquisa. Para essa escolha estabelecemos que os seguintes critérios devessem ser atendidos simultaneamente: possuir surdez total, não possuir aparelho auditivo, compreender Língua Portuguesa escrita total ou parcialmente e se declarar fluente em LIBRAS. Essa escolha se baseou principalmente nos perfis de pesquisa já abordados por outros pesquisadores e apresentados na fundamentação teórica desse trabalho, certificando-se que os alunos escolhidos estivessem dentro das mesmas condições e que possuíssem surdez total, chegamos a três sujeitos.

No Quadro 2 apresentamos as características principais dos alunos entrevistados. Para preservar a identidade dos mesmos seus nomes foram mantidos em sigilo e para isso foram adotados os termos Aluno 1, Aluno 2 e Aluno 3.

Quadro 2 - Perfil dos alunos selecionados como sujeitos de pesquisa da segunda etapa da pesquisa

\begin{tabular}{l|c|c|c}
\hline \multicolumn{1}{c|}{ Características } & Aluno 1 & Aluno 2 & Aluno 3 \\
\hline Possuir surdez total? & Sim & Sim & Sim \\
\hline Utiliza aparelho auditivo? & Não & Não & Não \\
\hline Tem LIBRAS como língua materna? & Sim & Sim & Sim \\
\hline É fluente em LIBRAS? & Sim & Sim & Sim \\
\hline Compreende Língua Portuguesa? & Parcialmente & Parcialmente & Parcialmente \\
\hline
\end{tabular}

Fonte: Autoria própria (2017). 
Ao verificarmos as características dos alunos, percebemos que todos compreendem apenas parcialmente a Língua Portuguesa. Entretanto, todas as aulas e todos os materiais a que eles têm acesso encontram-se nessa Língua, a divergência linguística aqui observada imprimirá suas consequências nos demais resultados que serão discutidos posteriormente.

Sobre as dificuldades de aprendizagem

A entrevista realizada foi formulada com doze perguntas abertas que objetivavam diagnosticar as dificuldades dos alunos surdos na aprendizagem da disciplina de Química. As questões foram redigidas a partir das características apontadas por Gil (2002), assim, elas eram fechadas, porém tinham uma ampla possibilidade de respostas, pois todas estavam diretamente ligadas ao problema de pesquisa, bem como foram feitas em uma pequena quantidade começando pelas mais simples e finalizando com as mais complexas e as perguntas não sugeriram respostas. $\mathrm{O}$ emprego desta etapa metodológica deu-se durante a aula de exercícios de Química, quando os alunos foram mantidos em sala e o intérprete das aulas esteve presente, porém não houve necessidade da sua intervenção já que os sujeitos tiveram acesso às questões traduzidas e gravadas em vídeo na Língua de Sinais, garantindo que o instrumento não sofreu influência dos aplicadores. Os alunos levaram em torno de 50 minutos para responder às questões.

Para sistematização dos resultados foram elaboradas quatro categorias, sendo a primeira denominada - Afinidade com a disciplina - que compreendia quatro questões discursivas e as respostas obtidas estão apresentadas no Quadro 3 , a seguir.

Quadro 3 - Categorização de acordo com a afinidade com a disciplina de Química.

\begin{tabular}{c|c}
\hline \multicolumn{2}{c}{ Categoria: Afinidade com a disciplina gosta de Química? Por quê? } \\
\hline Aluno 1 e Aluno 2 & Gosta de química por causa da matemática. \\
\hline Aluno 3 & Gosta de química por causa do professor. \\
\hline Qual o conteúdo de Química você mais gosta? Por quê? \\
\hline Aluno 1 & Solubilidade. \\
\hline Aluno 2 & Não especificou. \\
\hline Aluno 3 & Massa molar. \\
\hline Qual o conteúdo de Química você menos gosta? Por quê? & Gráficos. \\
\hline Aluno 1 e Aluno 3 & Não especificou. \\
\hline Aluno 2 & Resposta inaudível \\
\hline Você gosta das aulas de Química? Por quê? \\
\hline Aluno 1
\end{tabular}


O objetivo da primeira questão foi avaliar a aceitação da disciplina de Química pelo aluno e o motivo disso. Os três sujeitos de pesquisa alegaram gostar da disciplina por diversos motivos, como o apreço da aproximação com a Matemática, por afinidade com o professor regente e por se interessar pelo conteúdo. O Aluno 1, por exemplo, respondeu: "Gosto muito porque gosto de matemática e número". A Matemática é uma das disciplinas ligadas à Química e comumente aparece como obstáculo de aprendizagem em pesquisas com alunos surdos e ouvintes (Aroldo Junior; Ramos, 2008). Segundo Borges e César (2012), para que a Matemática se torne mais inclusiva, as práticas em aula devem incorporar atividades especialmente concebidas para facilitar aos alunos o acesso e a partilha de ferramentas culturais das suas próprias comunidades. Nesse sentido, as autoras salientam a importância da reflexão sobre as próprias práticas, de uma forma sistemática, sustentada, crítica e ponderada, que deverá ter em vista a adequação das mesmas às características, necessidades e interesses dos alunos.

Sob o olhar de Guarinello et al. (2006), é fundamental que os professores passem a relacionar suas ações com as dificuldades de seus alunos em aprender. Durante sua pesquisa em salas de inclusão em uma escola no Paraná, os autores observaram que não havia esse movimento de auto avaliação por parte dos professores e os obstáculos observados dentro da sala de aula eram justificados pela complexidade da LIBRAS e pela falta da alfabetização em Português dos alunos surdos.

A segunda pergunta buscou identificar quais os conteúdos de Química os alunos mais gostavam e o motivo. Ocorreu que os sujeitos não se lembravam dos nomes dos conteúdos já estudados e, em geral, acabaram por citar os que estavam estudando no momento. A justificativa da escolha desses conteúdos deu-se com base na facilidade ou dificuldade de compreensão dada pelo próprio conteúdo, como discorre o Aluno 1: "Solubilidade porque é muito fácil". Certamente, as respostas dos alunos estão diretamente relacionadas à motivação dos mesmos sem aprender com práticas inovadoras, ou seja, metodologias distintas, que segundo Rocha et al. (2015) são imprescindíveis para transpor as barreiras impostas pelo vocabulário e pela complexidade inerente da disciplina de Química. Durante a aula de solubilidade, a intérprete não conseguia exemplificar para os alunos o que era concentração, e foi a partir de um exemplo abordando a preparação de uma bebida achocolata feita com mais ou menos achocolatado, que os alunos conseguiram compreender o conceito de concentração e solubilidade. Para Gatti (2015), aprender Ciências é adentrar uma cultura diferente que requer experiências diferentes, métodos diferentes e formas de expressão características.

A terceira indagação pretendeu relacionar os conteúdos de Química menos apreciados pelos alunos e descobrir o motivo desse apontamento. Conforme o ocorrido nas questões anteriores, os alunos tiveram dificuldades em lembrar-se dos conteúdos já estudados e acabaram por citar os trabalhados no trimestre vigente. Esse fato pode ter sido agravado pela exposição das notas trimestrais ditas pelo professor, levando-os a relacionar o baixo desempenho ao desgosto pelo conteúdo recém-trabalhado, que foi Representação e Análise Gráfica. Apenas o Aluno 2 respondeu: "Nada". Seguindo o mesmo raciocínio de Guimarães; Gitirana; Roazzi (2001), utilizado na segunda interrogação, apesar de os gráficos serem recursos fundamentalmente visuais, a maioria dos alunos, o que não se restringe 
somente a alunos surdos, sente muita dificuldade em interpretar seus resultados. Essa questão torna-se um empecilho para que o aluno assimile esse conteúdo a algo prazeroso. Desta forma, faz-se necessário propor metodologias que atendam especificamente a necessidade do seu público alvo, não exclusivamente, nesse caso, os alunos surdos, mas sim todos os alunos da classe, já que nenhum deles obteve um bom desempenho durante o trimestre. Segundo Moraes et al. (2004) é necessário que metodologias sejam repensadas, substituídas e propagadas a fim de auxiliarem no processo de ensino e aprendizagem desses alunos.

O objetivo da quarta inquirição foi verificar se os alunos gostavam das aulas de Química e por quê. Os três sujeitos responderam que aprovam as aulas, mas por motivos diferentes, seja pela aproximação com cálculos, seja porque há a necessidade de aprender ou por afinidade com o professor, como declara o Aluno 3: "Prof é bom gente, porque Ela sempre ensa muito as aulas aulas sem ender muito falar prof.". Para Barbosa e Pacheco (2014), uma das limitações encontrada dentro da sala de aula está atrelada ao fato do professor não ser proficiente em LIBRAS. Isso torna ainda mais difícil a aprendizagem, pois os alunos não conseguem reportar-se diretamente ao professor o que não colabora para que seja estreitado o vínculo professor-aluno. Quando o Aluno 3 responde que gosta das aulas de Química, ele se justifica pelo fato do professor não saber LIBRAS e ainda assim tentar ensina-los. Observa-se nesse ponto, que se houvesse uma comunicação em Língua Brasileira de Sinais entre professor e alunos haveria um melhor relacionamento dentro da sala de aula, o que, consequentemente traria ganhos positivos. Segundo Santos (2001), a relação professor-aluno é um aspecto fundamental para a aprendizagem, e é ela que vai definir os caminhos da aprendizagem, pois, conforme essa interação se dá, a aprendizagem do aluno torna-se mais ou menos facilitada. A autora aponta que não são as características de personalidade do professor que influenciam esse relacionamento, mas sim suas ações em sala de aula que determinam como essas interações irão dar-se.

O relacionamento entre professor e aluno é reflexo direto da prática pedagógica, especificamente no tocante aos procedimentos adotados e tem por finalidade promover o desenvolvimento do aluno, ponderando sua vivência externa às paredes da escola e os relacionamentos que este estabelece (VYGOTSKY, 2009). Para o autor, esse relacionamento é fundamental e deve esquadrinhar a metodologia utilizada, pois quando o aluno identificam aspectos familiares dentro da sala de aula ele desenvolve novas habilidades e a surdez passa a ser vista como uma peculiaridade e não como uma dificuldade ou impedimento para que a aprendizagem se dê da melhor forma.

A segunda categoria de análise - Dificuldades de Aprendizagem compreendia duas questões discursivas e as respostas obtidas estão apresentadas no Quadro 4. 
Quadro 4 - Categorização das questões sobre as dificuldades de aprendizagem.

Categoria: Dificuldades de aprendizagem

Qual o conteúdo de química você sentiu mais dificuldade em aprender? Por quê?

\begin{tabular}{|c|c|}
\hline Aluno 1 e Aluno 3 & $\begin{array}{l}\text { Sentiu mais dificuldade em análise de } \\
\text { gráficos. }\end{array}$ \\
\hline Aluno 2 & $\begin{array}{l}\text { Sentiu mais dificuldade em aprender } \\
\text { solubilidade. }\end{array}$ \\
\hline \multicolumn{2}{|c|}{ Qual a maior dificuldade que você encontrou para aprender química? Por quê? } \\
\hline Aluno 1 e Aluno 3 & $\begin{array}{l}\text { Maior dificuldade com interpretação de } \\
\text { gráficos. }\end{array}$ \\
\hline Aluno 2 & $\begin{array}{c}\text { Maior dificuldade envolvendo Língua } \\
\text { Portuguesa e surdez. }\end{array}$ \\
\hline
\end{tabular}

Fonte: Autoria própria (2017).

A quinta questão visou elencar quais conteúdos de Química o aluno sentiu mais dificuldade em aprender e o porquê disso. Todos os sujeitos de pesquisa tiveram dificuldades na elaboração das respostas, pois não se lembravam dos conteúdos trabalhados anteriormente e acabaram por citar os trabalhados durante o trimestre vigente. O conteúdo mais citado foi análise de gráfico, o que condiz com as respostas dadas na terceira pergunta. Segundo Guimarães et al. (2001), os gráficos são um importante recurso para a resolução de problemas do cotidiano e é preciso que os alunos tenham clareza que interpretar gráficos referese à habilidade de ler, ou seja, de extrair sentido dos dados e, que construir um gráfico refere-se à geração de algo novo que exige a seleção de dados, de descritores, de escalas e do tipo de representação mais adequado. Em sua pesquisa, realizada com alunos ouvintes da 6a série, de uma escola pública sobre a interpretação de gráficos, apenas um aluno, conseguiu fazer a interpretação correta dos dados. Portanto, observa-se que esse recurso, apesar de ser predominantemente visual, ainda é um obstáculo durante a aprendizagem. Pesquisas como a de Monteiro (2011) destacam que a diferença linguística durante as aulas tem afetado diretamente a maneira como esses alunos aprendem. $O$ autor enfatiza a importância de identificar essas dificuldades e saná-las da melhor maneira possível.

O sexto questionamento estave direcionado a elencar as dificuldades que o aluno surdo encontrou para aprender Química e o porquê disso. As respostas foram variadas e envolveram a capacidade de compreensão de gráficos e de desenvolvimento de cálculos essenciais da Química. Novamente a utilização de recursos didáticos que atendam especificamente as necessidades do seu público alvo é apontada (MORAES et al., 2004), fica evidente a existência dessa lacuna dentro de uma sala de aula inclusiva. Apenas o Aluno 2 relatou a língua portuguesa como empecilho de aprendizagem, como aparece a seguir: "Estão poque eu sou surdo tenh confusão por portugês frase por esse difícil.". Dentro do campo da Psicologia, Vygotsky (2009) salienta que o desenvolvimento da linguagem se dá através de processos cognitivos mediados pela cultura e por processos sócio históricos a que o sujeito é submetido. $O$ autor enfatiza que a aquisição da linguagem é um ato muito mais cultural do que uma atividade biológica e para ele, o pensamento e a linguagem são indissociáveis. A linguagem é responsável pela regulação da atividade psíquica humana, pois é ela que permeia a estruturação dos processos cognitivos. Assim, é assumida como constitutiva do sujeito, pois 
possibilita interações fundamentais para a construção do conhecimento. A diferença linguística presente na classe de inclusão torna o surdo um estrangeiro que tem acesso aos conhecimentos de um modo diferente dos demais e se mantém isolado do grupo, de modo que isso o impossibilita de aprender como os demais, já que a aprendizagem é um constante movimento de troca de saberes, e acaba assim por se tornar um precursor da não aprendizagem (LACERDA, 2006).

A terceira categoria de análise - Relação com o professor e o intérprete compreendia quatro questões discursivas e as respostas obtidas estão apresentadas no Quadro 5.

Quadro 5 - Categorização das questões sobre a relação com professor e intérprete Categoria: Relação com o professor e o intérprete

Durante a aula de química, você presta mais atenção no professor ou no intérprete? Por quê?

\begin{tabular}{c|c}
\hline Aluno 1 & Presta mais atenção no professor. \\
\hline Aluno 2 e Aluno 3 & Presta mais atenção no intérprete. \\
\hline O professor relaciona os conteúdos de química com situações comuns do seu dia a dia? \\
\hline Aluno 1, Aluno 2 e Aluno 3 & $\begin{array}{c}\text { Afirma que o professor relaciona os } \\
\text { conteúdos com o dia a dia. }\end{array}$ \\
\hline Se você fosse professor de química, como você faria para que seus alunos aprendessem \\
melhor a matéria?
\end{tabular}

Fonte: Autoria própria (2017).

O objetivo da sétima indagação foi verificar em quem o aluno surdo prestava mais atenção durante a aula de Química, se no professor ou no intérprete. O Aluno 1 respondeu à questão dizendo que presta mais atenção no professor e cabe aqui destacar que esse aluno tem mais facilidade com a Língua Portuguesa que os demais sujeitos os alunos 2 e 3 afirmaram prestar mais atenção no intérprete e em destaque está à resposta do Aluno 2: "Dois mas mais dicil olhar um dos professor e interprete que prefiro interprete porque professor não sabe LIBRAS só presto atenção que professor explicar no quadro". Em concordância com Guarinello et al. (2006), os professores relacionam as dificuldades de aprendizagem com as questões fisiológicas que a surdez implica, porém, mais do que a prática pedagógica, o relacionamento e o conhecimento da LIBRAS têm implicações diretas nesse processo.

A oitava pergunta buscou verificar o uso da contextualização pelo professor, como intuito de aproximar o conteúdo trabalhado à realidade do aluno. Todos os sujeitos de pesquisa responderam que há essa relação, fato que pode ser confirmado durante o período de observação das aulas. A entrevista realizada por Schneider (2006) aborda essa questão com clareza quando aponta o interesse que os professores demonstram em desenvolver práticas que incluem o aluno surdo. Entretanto, nem sempre se sentem capacitados adequadamente para que o façam, o que acaba comprometendo, não só a atividade docente, mas também a discente, prejudicando ambas as partes. 
O nono questionamento objetivou supor a troca de papéis, em que o sujeito surdo estaria no papel de professor e avaliar qual seria sua postura metodológica frente aos alunos. Os sujeitos de pesquisa revelaram visões bastante diferentes, seja uma abordagem mais tradicional, com aplicação de tarefas de casa, seja com o uso de quadro de giz e atividades. Em destaque, temos a resposta do Aluno 2: "Eu usar slide porque surdos visual.". Há várias pesquisas que buscam identificar quais são as principais dificuldades enfrentadas dentro de uma sala de aula inclusiva, porém, poucas delas dão voz aos sujeitos em questão (ALMEIDA; TEIXEIRA, 2011). Desvendar essas dificuldades a partir da opinião dos alunos, não somente dos professores e intérpretes desmistifica a visão de que uma boa prática docente está alicerçada nos saberes do professor e no que este julga o ideal para sua turma (NETO et al., 2015) é fundamental que o próprio aluno possa ser ouvido e que a partir de suas necessidades novas metodologias sejam elaboras. Uma das principais contribuições de Vygotsky foi à elucidação da teoria da ZDP, na qual o aluno passa a dominar novas habilidades a partir da ação de um mediador. $O$ conceito de mediação deste teórico configura a influência do professor como atuante durante o processo de aprendizagem, e afirma também a importância de se investigar e avaliar em qual estágio de desenvolvimento o discente se encontra, partindo da exiguidade do aluno para conceber metodologias que promovam o conhecimento de maneira indistinguível, extinguindo assim, os obstáculos impostos a uma turma de inclusão (VYGOTSKY, 2008).

A quarta categoria de análise - LIBRAS e a Química - compreendia três questões discursivas e as respostas obtidas estão apresentadas no Quadro 6, a seguir.

Quadro 6 - Categorização das questões sobre LIBRAS e a Química Categoria: LIBRAS e a Química

Você tem acesso a algum material de Química que possua LIBRAS? Qual?

Aluno 1, Aluno 2 e Aluno 3

Não possui material.

Você sente dificuldade para compreender algum sinal de termos químicos durante a aula de química?

\begin{tabular}{c|c}
\hline Aluno 1 e Aluno 2 & Sente dificuldade. \\
\hline Aluno 3 & Sente pouca dificuldade. \\
\hline Os termos químicos são criados juntamente com o intérprete? \\
\hline Aluno 1 e Aluno 2 & Termos são criados em conjunto. \\
\hline Aluno 3 & Resposta inconclusiva. \\
\hline
\end{tabular}

Fonte: Autoria própria (2017).

A décima questão teve como objetivo verificar se os alunos tinham acesso a algum material didático de Química em LIBRAS. Todos os sujeitos de pesquisa relataram não possuir acesso a esse tipo de material ou desconhecer a existência. O Aluno 3 escreveu o seguinte: "Não tem:(mas eu quero muito", expressando o desconforto por não possuir nenhum recurso didático em LIBRAS. A produção de materiais em Língua Brasileira de Sinais tem sido ampliada no Brasil. Entretanto, o processo educacional inclusivo e a conquista dos direitos linguísticos das pessoas surdas têm apontado para a necessidade de produção de materiais didáticos traduzidos para LIBRAS. Porém, a inserção desses recursos em sala de aula, 
depende da capacitação dos professores, a fim de que consigam aplica-los de forma efetiva em sala de aula (ALBUQUERQUE et al., 2014).

A décima primeira indagação fez referência às possíveis dificuldades de compreensão de sinais com terminologias Químicas apresentadas pelos alunos surdos. Dois sujeitos de pesquisa afirmaram ter dificuldades e o Aluno 2 respondeu o seguinte: "Médio porque alguns sinais diferente que eu não conheço". Os intérpretes que participaram da pesquisa de Santigo (2014) relatam que a sua principal dificuldade está atrelada à variedade linguística e a falta de sinais específicos da disciplina. Durante a observação, pode-se notar que quando não havia sinal específico, o intérprete soletrava/dedilhava a palavra em LIBRAS, sem que houvesse um trabalho em conjunto para a criação de um sinal, o que demandaria tempo da aula. Aulas baseadas em dinâmicas visuais, em que os alunos participam e entendem os conceitos, fora ou dentro do espaço formal de ensino são reconhecidamente favoráveis ao ensino inclusivo de Química. Para Quadros (2003), o uso dessas técnicas visuais torna mais próximo o conteúdo da disciplina, conciliando o nível macroscópico com o nível microscópico, seja para alunos surdos ou ouvintes.

A décima segunda questão objetivou avaliar como se dá a criação e a apropriação de termos químicos não padronizados em LIBRAS. Houve uma variedade de respostas, dentre as quais os Alunos 1 e 2 afirmaram que sim, os termos são criados junto ao intérprete, e o Aluno 3 escreveu que "Sim, tenho, mas pode inverto letras outura LIBRAS", o que não ficou claro para fins de interpretação, tornando a resposta inconclusiva. A prática docente está vinculada diretamente a como se dá o processo de ensino e aprendizagem, porém os resultados obtidos mostram que a falta de capacitação e aprimoramento são elementos que impossibilitam a mediação feita pelo professor de alcançar efetivamente os alunos surdos. A distinção linguística é outro fator que tem se colocado como obstáculo dentro das salas de aula de inclusivas, que mesmo com a presença do intérprete está longe de ser sanada, pois há uma crescente precariedade na formação desse profissional que não pode ser visto só como professor do aluno surdo, mas deve exercer a função de traduzir para a sua língua materna o conhecimento que é transmitido através da mediação do professor regente. Para Vygotsky (2008), todo o processo de aprendizagem está diretamente relacionado à interação do sujeito com o meio externo e a maneira como o aluno constrói pontes entre os saberes cotidianos e os conhecimentos científicos são responsáveis por minimizar os obstáculos inerentes da escolarização, independentemente de quais sejam as disciplinas.

A necessidade de materiais didáticos elaborados de acordo com as características do grupo é crescente, bem como a inserção desses nas práticas pedagógicas inclusivas. Foi observado que a dificuldade dos alunos não está intimamente ligada aos conteúdos químicos, mas sim ao tipo de linguagem utilizada em sala de aula, seja ela uma representação e análise gráfica ou a falta da utilização da LIBRAS.

\section{CONSIDERAÇÕES FINAIS}

Tradicionalmente conhecido na cidade por receber alunos de inclusão, o Colégio, lócus da investigação, conta com intérpretes em todas as salas que 
possuem alunos surdos, fornecendo-nos um rico campo de pesquisa, possibilitando diagnosticar e analisar os aspectos interessantes da comunidade surda dessa escola e, essencialmente, em relação à disciplina de Química.

Como resultado dessa pesquisa conseguimos elencar, apoiadas na teoria de mediação de Vygotsky, que o maior obstáculo de aprendizagem em Química é a diferença linguística, seguida pela falta de conhecimento de LIBRAS pelo professor, bem como pela dificuldade na compreensão de sinais de terminologias químicas já existentes ou na criação de novos sinais, a não formação acadêmica específica dos intérpretes e na ausência de materiais didáticos em LIBRAS e de metodologias que preconizam as imagens. Pesquisas recentes nos campos de ensino da Biologia e da Física (SILVA; CORDOVA, 2014; ROCHA et al., 2015; BOTAN; PAULO, 2014) ressaltam esses mesmos problemas, indicando a necessidade de que os pesquisadores voltem seus olhares para a inserção de alunos com especificidades de aprendizagem nas turmas regulares e assim passem a utilizar metodologias que os alcancem, certificando-se que o Ensino de Ciências abranja todas as áreas fazse necessário aprofundar essas questões no que diz respeito à Química.

Podemos inferir que as dificuldades que os alunos surdos enfrentam para aprender Química estão relacionadas ao contexto no qual estão inseridos. Interpretação gráfica, solubilidade e falta de sinais para termos químicos foram apontados como obstáculos de aprendizagem quanto à disciplina. Entretanto existe a preocupação de que esses sujeitos estejam na sala de aula regular e questões tão importantes como a variedade linguística imposta a esse meio não sejam tratadas como deveria. Essa lacuna priva os alunos de realmente participarem do processo de ensino e aprendizagem, tornando-os meros expectadores.

As dificuldades relacionadas aos conteúdos químicos não são características exclusivas de um determinado grupo de estudantes e devem ser repensadas na Educação em sua totalidade. Por exemplo, materiais didáticos desenvolvidos para atender questões particulares de uma parcela da comunidade escolar, podem muitas vezes apresentar contribuições significativas em sala de aula, incluindo todos os educandos no processo educativo. A ação docente inclusiva deve ser repensada e incorporada nas práticas pedagógicas cotidianas, bem como no processo de formação inicial de professores de Química. Esperamos, com a nossa pesquisa, incentivar os educadores a buscarem novos meios de abordar os conteúdos químicos em sala de aula. Além disso, reforçamos a importância das pesquisas e práticas que tomem como base a Educação Inclusiva, da percepção atenta e sensível às necessidades dos estudantes surdos, pois são eles os protagonistas nesse processo e os que nos darão os direcionamentos fundamentais para que possamos elaborar materiais didáticos e metodologias de ensino inclusivo. 


\title{
Case study on learning difficulties of deaf students in the Chemistry subject
}

\begin{abstract}
This paper analyzes the difficulties of learning in the Chemistry subject, from the perspective of deaf students inserted in an ordinary public school, constituting a qualitative research of the Case Study type. Based on bibliographical contribution that involves Inclusive Education and taking the observation as a fundamental instrument for the constitution of data were accompanied 20 classes of Chemistry, during the 12 weeks. A questionnaire was applied to the eight deaf students of a class, in order to diagnose the profile of the research subjects and to select the students who would participate in the later stage, contemplating an interview. Thus, three students - who met the criteria established: total deafness, no hearing aid, understand at least partially the Portuguese Language - participated in the structured interview with the purpose of identifying their perceptions and difficulties in the Chemistry subject. The results showed that the greatest obstacle to learning in Chemistry is the linguistic difference, followed by the teacher's lack of knowledge of LIBRAS (Brazilian Sign Language), the difficulty in understanding the signs of existing chemical terminologies or the creation of new signs, the absence of specific academic background of the interpreters and the lack of teaching materials in LIBRAS and methodologies that make use of images as didactic resources. Therefore, the importance of improving teaching materials and methodologies that meet the particularities of an inclusion class, knowing the needs pointed out by the deaf students themselves are highlighted.
\end{abstract}

KEYWORDS: Learning difficulties. Chemistry. Deaf students. Chemistry teaching. 


\section{REFERÊNCIAS}

ALBUQUERQUE, K. M. C.; MONTEIRO. R. F. F. V. M. A Tradução de Material Didático de Química para a Língua Brasileira De Sinais. Cultura e Tradução, Paraíba, v.2, n. 1, p. 116-140, 2014. Disponível em:

<http://www.ies.ufpb.br/ojs2/index.php/ct/article/view/21103/11619>. Acesso em: 24 abr. 2016.

ALMEIDA, J. L.; TEIXEIRA, J. G. Reflexões acerca da inclusão de alunos com surdez em aulas de Química. Uberlândia: Facip, 2011, p. 1 -12. Disponível em: <http://www.nutes.ufrj.br/abrapec/viiienpec/resumos/R0605-1.pdf>. Acesso em: 22 mai. 2016.

AROLDO JUNIOR, H.; RAMOS, M. G. Matemática para pessoas surdas: Proposições para o Ensino Médio. In: SIMPÓSIO INTERNACIONAL DE PESQUISA EM EDUCAÇÃO MATEMÁTICA, 2. Recife, 2008. Anais... . Recife SIMPEM, 2008, p. 1-12. Disponível em: < http://www.sbembrasil.org.br/sbembrasil/index.php/anais/sipem>. Acesso em: 03 abr. 2016.

BARBOSA, K. C. M.; PACHECO, D. Química e Surdez: novas propostas no processo de ensino. In: IV SIMPÓSIO NACIONAL DE ENSINO DE CIÊNCIA E TECNOLOGIA, 4. Ponta Grossa, 2014. Anais... Ponta Grossa: SINECT, 2014, p. 1 -12. Disponível em: < http://www.sinect.com.br/anais2014/ensino-de-ciencias.html>. Acesso em: 03 abr. 2016.

BARDIN L. Análise de conteúdo. 1 ed. Lisboa: Editora Edições 70, 1977.

BRASIL, Lei n.9.394, de 20 de dezembro de 1996. Lex: Diário Oficial da República Federativa do Brasil, Poder Executivo, Brasília, Distrito Federal, 1996. Legislação Federal e marginalia. Disponível em:

<http://www.planalto.gov.br/ccivil_03/leis/L9394.htm>. Acesso em: 04 mar. 2016.

BRASIL. Lei 10.436, de 24 de abril de 2002. Lex: Diário Oficial da República Federativa do Brasil, Poder Executivo, Brasília, Distrito Federal, 1996. Legislação Federal e marginalia. Disponível em:

<http://www.planalto.gov.br/ccivil_03/leis/2002/l10436.htm>. Acesso em: 04 mar. 2016.

BRASIL, Decreto n.5.626, de 22 de dezembro de 2005. Lex: Diário Oficial da República Federativa do Brasil, Poder Executivo, Brasília, Distrito Federal, 2005. Legislação Federal e marginalia. Disponível em: 
BORGES, I.; CÉSAR, M. Eu leio, tu ouves, nós aprendemos: Experiências de aprendizagem matemática e vivências de inclusão de dois estudantes Surdos, no ensino regular. Interacções, v. 1, n. 1, p. 141-180, 2012. Disponível em: <http://repositorio.ul.pt/handle/10451/5968>. Acesso em: 08 ago. 2016.

BOTAN, E.; PAULO, I. J. C. Ensino de física para surdos: Três estudos de casos da implementação de uma ferramenta didática para o ensino de cinemática.

Experiências no Ensino de Ciências, v. 9, n. 1, p. 1-27, 2014. Disponível em: < http://if.ufmt.br/eenci/artigos/Artigo_ID229/v9_n1_a2014.pdf>. Acesso em: 14 mai. 2017.

GATTI, I. C. Abordagem temática no ensino de química: solubilidade e polaridade de substâncias orgânicas. ENSINO \& PESQUISA - Revista Multidisciplinar de Licenciatura e Formação Docente, v. 13, n. 01, 2015. Disponível em: <http://periodicos.unespar.edu.br/index.php/ensinoepesquisa/article/view/593> Acesso em: 11 jul. 2016.

GERHARDT, T. E.; SILVEIRA, D. T. Métodos de pesquisa. 1. ed. Rio Grande do Sul: Plageder, 2009.

GIL, A. C. Como elaborar projetos de pesquisa. 4. ed. São Paulo: Atlas, 2002.

GUARINELLO, A. C.; BERBERIAN, A. P.; SANTANA, A. P.; MASSI, G.; PAULA, M., A inserção do aluno surdo no ensino regular: visão de um grupo de professores do estado do Paraná. Revista Brasileira de Educação Especial, Marília, v.12, n.3, 2006, p.317-330. Disponível em:

$<$ http://www.scielo.br/scielo.php?script=sci_abstract\&pid=S1413$65382006000300003 \&$ Ing=en\&nrm=iso\&tlng=pt>. Acesso em: 09 jun. 2016.

GUIMARÃES, G. L.; GITIRANA V.; ROAZZI A. Interpretando e construindo gráficos. In: REUNIÃO ANUAL DA ASSOCIAÇÃO NACIONAL DE PÓS-GRADUAÇÃO E PESQUISA EM EDUCAÇÃO, 24. Caxambu, 2001. Anais... . Caxambu: ANPED-GT Educação Matemática 2001, p. 1-12.

LACERDA, C. F. A inclusão escolar de alunos surdos: o que dizem alunos, professores e intérpretes sobre esta experiência. Cad. Cedes, Campinas, v. 26, n. 69, p. 163-184, 2006. Disponível em: $<$ http://www.scielo.br/scielo.php?script=sci_abstract\&pid=S010132622006000200004\&lng=en\&nrm=iso\&tlng=pt>. Acesso em: 06 mar. 2016.

LAKATOS, E. M.; MARCONI, M. A. Técnicas de pesquisa. 3 ed.. São Paulo: Editora Atlas, 1996. 
LIPPE, E. M. O.; CAMARGO, E. P. O ensino de ciências e seus desafios para a inclusão: o papel do professor especialista. In: NARDI, R. Ensino de ciências e matemática I: temas sobre a formação de professores. São Paulo: Unesp, 2009. 258 p. Disponível em: <http://books.scielo.org/id/g5q2h>. Acesso em: 02 set. 2016.

LORENZETTI, M. L. A inclusão do aluno surdo no ensino regular: a voz das professoras. Dissertação (mestrado em Educação Científica e Tecnológica). 2001. Universidade de Santa Catarina. Disponível em: <http://repositorio.ufsc.br/xmlui/handle/123456789/79505>. Acesso em: 03 mar. 2016.

LÜDKE, M.; ANDRÉ, M. Pesquisa em Educação: abordagens qualitativas. 2. ed. Rio de Janeiro: E.P.U, 2013.

MONTEIRO, J. H. S. O ensino de biologia e química para alunos surdos no ensino médio da rede pública da cidade de Fortaleza: Estudo de Caso 2011. Dissertação (Mestrado Profissional em Ensino de Ciências e Matemática) - Centro de Ciências, Universidade Federal do Ceará, Fortaleza, 2011. Disponível em: < http://www.repositorio.ufc.br/handle/riufc/1459>. Acesso em: 10 out. 2016.

MORAES, C. B.; CARVALHO, A. A. S.; DIAS, V. B.; MARGOTTO, L. M. A. K. Ensino de Biologia para alunos surdos: Contribuições do PIBID em uma Escola Pública no município de Itabuna - Bahia. In: CONGRESSO INTERNACIONAL DE EDUCAÇÃO E INCLUSÃO, 1. Bahia, 2004. Anais... . Bahia: CIEl, p. 1-10, 2004.

NETO, L. L.; ALCANTARA, M. M.; BENITE, C. R. M.; BENITE, A. C. O ensino de Química e a aprendizagem de alunos surdos: Uma interação mediada pela visão. In: ENCONTRO NACIONAL DE PESQUISA EM EDUCAÇÃO E CIÊNCIAS, 6. Goiás, 2007. Anais... . Goiás: ENPEC, 2015, v. 1, p. 1-12, 2015. Disponível em: <http://abrapecnet.org.br/atas_enpec/vienpec/search0.html>. Acesso em: 06. Jul. 2016.

QUADROS, R. M., Situando as diferenças implicadas na educação de surdos: inclusão/exclusão. Ponto de Vista: revista de educação e processos inclusivos, n. 5, p. 81-111, 2003. Disponível em:

$<$ https://periodicos.ufsc.br/index.php/pontodevista/article/view/1246>. Acesso em: 29 mar. 2017.

RAMOS, A. C. C. Ensino De Ciências \& Educação De Surdos: Um Estudo Em Escolas Públicas. (Mestrado em Ensino de Ciências) Instituto Federal de Educação, Ciência e Tecnologia do Rio de Janeiro Programa de Pós-Graduação Stricto Sensu em Ensino de Ciências., 2011. Disponível em: <http://www.ifrj.edu.br/webfm_send/3047>. Acesso em: 14 dez. 2016. 
ROCHA, L. R. M.; MORETTI, A. R.; COSTA, P. C. F.; COSTA. F. G. Educação de surdos: relato de uma experiência inclusiva para o ensino de ciências e Biologia. Revista Educação Especial, Santa Maria, v. 28, n. 52, p. 377-392, 2015. Disponível em: <http://www.redalyc.org/articulo.oa?id=313138442010>. Acesso em: 09 ago. 2016.

SANTIAGO, N. C. O ensino e a aprendizagem das Ciências dos alunos com surdez. Universidade Tecnológica Federal do Paraná. Medianeira, 2014. Disponível em: <http://repositorio.roca.utfpr.edu.br/jspui/bitstream/1/4383/1/MD_ENSCIE_II2 014_66.pdf>. Acesso em: 17 jan. 2017.

SANTOS, W. L. P.; SCHNETZLER, R. P. Ensino de Química para a cidadania: Um novo paradigma educacional. Educação em Química, ljuí: Unijuí, p. 119-144, 2003.

SANTOS, S. C. O processo de ensino-aprendizagem e a relação professor-aluno: aplicação dos sete princípios para a boa prática na educação de ensino superior. Caderno de pesquisas em administração, v. 8, n. 1 p. 69-82, 2001. Disponível em: $<$ http://www.scielo.br/scielo.php?script=sci_nlinks\&ref=000163\&pid=S0100$5502200800030000700024 \&$ lng=pt>. Acesso em: 03 set. 2016.

SCHNEIDER, R. Educação de surdos: inclusão no ensino regular. 1 ed. Passo Fundo: Ed. UPF, 2006.

SILVA, A. B. P.; PEREIRA, M. C. C. A imagem que professoras de escola regular têm em relação à aprendizagem do aluno surdo. Rev. Estudos de Psicologia, Campinas, v. 20, n. 2, p. 5-13, 2003. Disponível em: <http://www.scielo.br/pdf/estpsi/v20n2/v20n2a01.pdf>. Acesso em: 19 jul. 2016.

SILVA, E. L.; MENEZES, E. M. Metodologia da pesquisa e elaboração de dissertação. Apud Young e Lundberg, Revista Atual, Florianópolis, v. 4, 2005, p. 138. Disponível em:

<https://projetos.inf.ufsc.br/arquivos/Metodologia_de_pesquisa_e_elaboracao_ de_teses_e_dissertacoes_4ed.pdf $>$. Acesso em: 30 out. 2016.

SILVA, L. M.; CORDOVA, B.C. Criação de material adaptado ao ensino de Biologia para sujeitos surdos. Repositório Institucional Uniceub, Brasília, 2014. Disponível em: <http://hdl.handle.net/235/6321>. Acesso em: 14 mai. 2017.

SOUSA, F. S.; SILVEIRA, H. E. Terminologias Químicas em LIBRAS: a utilização de sinais na aprendizagem de alunos surdos. Química Nova na Escola, v. 33, n. 1, 
SPENASSATO, D.; GIARETA, M. M. K. Inclusão de alunos surdos no Ensino Regular: Investigação das propostas Didático-Metodológicas desenvolvidas por professores de Matemática no Ensino Médio da EENAV. In: ENCONTRO GAUCHO DE EDUCAÇÃO MATEMÁTICA, 10. Rio Grande do Sul, 2009. Anais... . Rio Grande do Sul: EGEM, 2009, p. 1-12. Disponível em: <

http://www.projetos.unijui.edu.br/matematica/cd_egem/fscommand/CC/CC_60. pdf>. Acesso em: 12 abr. 2016.

STAKE, R. E. The art of case study research. 1 ed. Londres: Sage, 1995.

VILELA-RIBEIRO, E. B.; BENITE, A. M. C. A Educação Inclusiva Na Percepção Dos Professores De Química. Ciência \& Educação, v. 16, n. 3, p. 585-594, 2010. Disponível em: <http://www.scielo.br/pdf/ciedu/v16n3/v16n3a06.pdf>. Acesso em: 02 abr. 2016.

VYGOTSKY, L. S. A Formação Social da Mente. Trad. José Cipolla Neto. 4. ed. São Paulo, Martins Fontes. 1991.

VYGOTSKY, L. S. Pensamento e linguagem. 1 ed. São Paulo: Relógio D'água. 2008.

VYGOTSKY, L. S. A imaginação e a arte na infância. 3 ed. São Paulo: Relógio D'água. 2009.

YIN, R. K. Estudo de Caso: planejamento e métodos. 2. ed. Porto Alegre: Bookman. 2001.

Recebido: 29 mai. 2017

Aprovado: 19 ago. 2017

DOI: $10.3895 /$ actio.v2n1.6773

Como citar:

SCHUINDT, C. C.; MATOS, C. F. de; SILVA, C. S. da. Estudo de caso sobre as dificuldades de aprendizagem de alunos surdos na disciplina de Química. ACTIO, Curitiba, v. 2, n. 1, p. 282-303, jan./jul. 2017. Disponível em: <https://periodicos.utfpr.edu.br/actio>. Acesso em: XXX.

Correspondência:

Cláudia Celeste Schuindt

Departamento de Química UFPR - Rua Coronel Francisco Heráclito dos Santos, 100, Jardim das Américas,

Curitiba, Paraná, Brasil.

Direito autoral: Este artigo está licenciado sob os termos da Licença CreativeCommons-Atribuição 4.0

Internacional.

(c) (i) 